\title{
Pathway Analysis of Metabolic Syndrome Using a Genome-Wide Association Study of Korea Associated Resource (KARE) Cohorts
}

\author{
Unjin Shim ${ }^{1}$, Han-Na Kim ${ }^{2}$, Yeon-Ah Sung ${ }^{3}$, Hyung-Lae Kim ${ }^{2 *}$ \\ ${ }^{1}$ Department of Internal Medicine, Seoul Seonam Hospital, Ewha Womans University Medical Center, Seoul 158-070,Korea, \\ ${ }^{2}$ Department of Biochemistry, Ewha Womans University School of Medicine, Seoul 158-710, Korea, \\ ${ }^{3}$ Department of Internal Medicine, Ewha Womans University School of Medicine, Seoul 158-710, Korea
}

\begin{abstract}
Metabolic syndrome (MetS) is a complex disorder related to insulin resistance, obesity, and inflammation. Genetic and environmental factors also contribute to the development of MetS, and through genome-wide association studies (GWASs), important susceptibility loci have been identified. However, GWASs focus more on individual single-nucleotide polymorphisms (SNPs), explaining only a small portion of genetic heritability. To overcome this limitation, pathway analyses are being applied to GWAS datasets. The aim of this study is to elucidate the biological pathways involved in the pathogenesis of MetS through pathway analysis. Cohort data from the Korea Associated Resource (KARE) was used for analysis, which include 8,842 individuals (age, $52.2 \pm 8.9$ years; body mass index, $24.6 \pm 3.2 \mathrm{~kg} / \mathrm{m}^{2}$ ). A total of 312,121 autosomal SNPs were obtained after quality control. Pathway analysis was conducted using Meta-analysis Gene-Set Enrichment of Variant Associations (MAGENTA) to discover the biological pathways associated with MetS. In the discovery phase, SNPs from chromosome 12, including rs11066280, rs2074356, and rs12229654, were associated with MetS ( $p<5$ $\times 10^{-6}$ ), and rs11066280 satisfied the Bonferroni-corrected cutoff (unadjusted $p<1.38 \times 10^{-7}$, Bonferroni-adjusted $p<$ 0.05). Through pathway analysis, biological pathways, including electron carrier activity, signaling by platelet-derived growth factor (PDGF), the mitogen-activated protein kinase kinase kinase cascade, PDGF binding, peroxisome proliferator-activated receptor (PPAR) signaling, and DNA repair, were associated with MetS. Through pathway analysis of MetS, pathways related with PDGF, mitogen-activated protein kinase, and PPAR signaling, as well as nucleic acid binding, protein secretion, and DNA repair, were identified. Further studies will be needed to clarify the genetic pathogenesis leading to MetS.
\end{abstract}

Keywords: genome-wide association studies, metabolic cardiovascular syndrome

\section{Introduction}

Metabolic syndrome (MetS) is a complex disorder related to type 2 diabetes mellitus (T2DM) and cardiovascular diseases, and its prevalence is continuously increasing worldwide [1, 2]. Insulin resistance, obesity, and inflammation are major factors leading to MetS; however, the effect of genetic and environmental factors cannot be ignored [3]. Sedentary lifestyle, decreased physical activity, high caloric intake, and westernized food habits are environmental factors leading to obesity and MetS [4, 5]. Parental and maternal obesity in early pregnancy is related to increased risk of childhood obesity, which could later lead to obesity in young adulthood $[6,7]$. In addition, family history of obesity, insulin resistance, and T2DM can increase the risk of MetS, implying the importance of genetic contribution. Candidate gene studies in MetS identified genes involved in glucose and insulin signaling, such as insulin receptor substrate 1 (IRS1), peroxisome proliferator-activated receptor $\gamma$ (PPARG), insulin-like growth factor 1 (IGF1), and genes involved in lipid metabolism, such as adiponectin (ADIPOQ), apolipoprotein A5 (APOA5), and low-density lipoprotein receptor $(L D L R)$ [3, 8-10]. Through genome-wide association

Received July 7, 2014; Revised September 5, 2014; Accepted September 12, 2014

*Corresponding author: Tel: +82-2-2650-5727, Fax: +82-2-2652-7846, E-mail: hyung@ewha.ac.kr

This is $2014 \mathrm{KNIH}$ KARE best paper awarded.

Copyright (C) 2014 by the Korea Genome Organization

(c) It is identical to the Creative Commons Attribution Non-Commercial License (http://creativecommons.org/licenses/by-nc/3.0/) 
studies (GWASs), a larger number of candidate genes could be further analyzed, and important susceptibility loci were discovered, including fat mass and obesity associated protein (FTO) and the melanocortin 4 receptor gene (MC4R), which were associated with body mass index (BMI) $[11,12]$. In another GWAS of MetS, the lipid locus at rs964184 was associated with high-density lipoprotein (HDL) - cholesterol and very low-density lipoprotein-cholesterol [13]. In a meta-analysis in Korea that used the GWAS results from the Korea Associated Resource (KARE) cohort, susceptibility loci in 12q24.11 and 12q24.13 were associated with HDLcholesterol levels, and genetic factors associated with osteoporosis and metabolic traits, such as T2DM, dyslipidemia, and obesity, could also be identified [14-16].

GWASs have their strengths in screening susceptible genes associated with complex diseases [17, 18]. However, GWASs focus more on individual single-nucleotide polymorphisms (SNPs) that meet a stringent statistical significance, rather than explaining the interaction of genes, and they can only explain a small portion of genetic heritability [19-21]. In addition, due to its small effect size, certain SNPs in a GWAS that have been identified to be associated with a disease might not show up in another study of the same disease. This can be seen in two published studies of T2DM and Crohn's disease, which could not find most of the proven susceptibility loci through GWASs and succeeded in achieving moderate significance after replication studies or meta-analysis [22, 23]. To overcome this limitation, pathway-based approaches have been introduced to improve the interpretability of the GWAS.

Pathway-based analysis integrates GWAS data with genes in the selected biological pathways or gene sets from predefined human databases [19, 24]. The strength of pathway analysis is its large effect size and higher power to detect genes that might have been missed through a GWAS [24-26]. Pathway analysis, such as Meta-analysis Gene-Set Enrichment of Variant Associations (MAGENTA), only requires the SNP p-values and chromosome positions, simplifying the analysis of GWASs [27]. MAGENTA analyzes the statistical power of GWASs through integration of variant association p-values into gene scores, correcting for confounding factors, such as gene size, SNP density, and linkage disequilibrium properties [27]. Through MAGENTA analysis, biological pathways associated with triglyceride, HDL-cholesterol, T2DM, and BMI have been identified [27-29]. Pathway analysis is a supplementary way to further analyze the results of GWASs. However, there are few studies that have used this approach to identify biological pathways associated with MetS in Asians. The aim of this study was to further elucidate the genomic data of the KARE cohort and to identify the biological pathways related with
MetS through a pathway-based approach.

\section{Methods}

\section{Subjects}

The cohort data from the KARE were used for the analysis. The KARE project, initiated in 2007, is a large cohort study that recruited two population studies from the rural Anseong and urban Ansan cohorts. We analyzed the data of 8,842 individuals (age, $52.2 \pm 8.9$ years; BMI, $24.6 \pm 3.2$ $\mathrm{kg} / \mathrm{m}^{2}$ ). Anthropometric measurements, including weight, height, and waist circumference, were measured in all subjects, and BMI was calculated $\left(\mathrm{kg} / \mathrm{m}^{2}\right)$. Systolic and diastolic blood pressures (BP) were examined in all subjects. Fasting plasma glucose and lipid profiles, including serum total cholesterol, HDL-cholesterol, and triglyceride levels, were measured after an overnight fast. Detailed information on the study protocol has been previously described by Cho et al. [16].

MetS was defined according to the modified Third Report of the National Cholesterol Education Program (NCEPATPIII) diagnostic criteria, which require the presence of three out of the five following factors: 1) abdominal obesity, defined through waist circumference, using the cut-off values for Asians ( $\geq 90 \mathrm{~cm}$ in men and $\geq 80 \mathrm{~cm}$ in women), 2) triglycerides $\geq 150 \mathrm{mg} / \mathrm{dL}$ or being on lipid-lowering treatment, 3) low HDL-cholesterol (men $<40 \mathrm{mg} / \mathrm{dL}$, women $<50 \mathrm{mg} / \mathrm{dL}$ ) or being on lipid-lowering treatment, 4) systolic/diastolic BP $\geq 130 / 85 \mathrm{~mm} \mathrm{Hg}$ or being on anti-hypertensive treatment, and 5) fasting plasma glucose $\geq 100 \mathrm{mg} / \mathrm{dL}$ or previous diagnosis of T2DM or anti-diabetic treatment [30, 31].

\section{Genome-wide association dataset analyses}

Genotyping was done using Affymetrix Genome-wide Human SNP Array 5.0 (Affymetrix Inc., Santa Clara, CA, USA). Samples with gender inconsistencies and low call rates $(<96 \%)$ were excluded.

Quality control $(\mathrm{QC})$ procedures were performed using PLINK version 1.07 [32]. Samples were excluded if there was a high missing call rate $(>5 \%)$, low minor allele frequency $(<0.05)$, or significant deviation from HardyWeinberg equilibrium $\left(\mathrm{p}<1 \times 10^{-6}\right)$. The total genotyping rate of the remaining individuals was $99.58 \%$. A total of 312,121 autosomal SNPs were obtained after QC, representing 8,842 individuals (4,183 males and 4,659 females). An additive model was used for the analysis. Detailed information on the quality control procedure of the genotypes is described elsewhere by Cho et al. [16]. 


\section{Pathway-based analysis}

Pathway analysis was conducted using MAGENTA (http://broadinstitute.org/mpg/magenta) to discover bio-

Table 1. Clinical and biochemical characteristics of subjects with metabolic syndrome and controls

\begin{tabular}{lcr}
\hline \multicolumn{1}{c}{ Characteristic } & \multicolumn{1}{c}{ MetS $(+)$} & \multicolumn{2}{c}{ MetS $(-)$} \\
$(\mathbf{n}=\mathbf{3 , 2 5 3})$ & \multicolumn{1}{c}{$(\mathbf{n}=\mathbf{5 , 5 8 9})$} \\
\hline Age $(\mathrm{y})$ & $54.3 \pm 8.8$ & $51.0 \pm 8.7$ \\
BMI $\left(\mathrm{kg} / \mathrm{m}^{2}\right)$ & $26.3 \pm 3.0^{*}$ & $23.6 \pm 2.9$ \\
Waist circumference $(\mathrm{cm})$ & $88.1 \pm 7.3$ & $79.4 \pm 8.6$ \\
Systolic BP $(\mathrm{mm} \mathrm{Hg})$ & $130.5 \pm 18.8^{*}$ & $116.5 \pm 16.4$ \\
Diastolic BP (mm Hg) & $85.5 \pm 11.3$ & $77.2 \pm 10.4$ \\
Triglyceride (mg/dL) & $201.9 \pm 119.3^{*}$ & $140.2 \pm 89.4$ \\
HDL-cholesterol (mg/dL) & $44.0 \pm 9.7^{*}$ & $45.0 \pm 10.3$ \\
FPG (mg/dL) & $85.3 \pm 30.5^{*}$ & $84.5 \pm 24.8$ \\
\hline
\end{tabular}

Values are presented as mean \pm standard deviation.

MetS, metabolic syndrome; $\mathrm{BMI}$, body mass index; BP, blood pressure; HDL, high-density lipoprotein; FPG, fasting plasma glucose.

$* p<0.05$ vs. MetS $(-)$ after controlling for age and sex. logical pathways or gene sets associated with MetS. Detailed information on this analysis is described by Segre et al. [27]. Briefly, the steps of MAGENTA analysis were as follows: 1) SNP association p-values and chromosome positions from the GWAS are used as input; 2) each gene located at a predetermined boundary is mapped to a single SNP; 3) based on the regional SNP p-values, gene scores are ranked, and the best SNP p-values are determined; 4) gene scores are corrected for confounding factors, such as gene size and linkage disequilibrium-related properties; and 5) gene set enrichment p-values are determined by analyzing the gene sets enriched with highly ranked gene scores and the selected biological pathway or gene sets [27]. False discovery rate (FDR) was also identified through multiple test correction. Additional information, including 95th and 75th percentile cutoffs and the number of observed and expected genes within each pathway, were also calculated. Since 75 th percentile cutoffs have greater power in interpreting complex diseases that are highly polygenic, this cutoff value was used for our interpretation [27, 29, 33].

Table 2. Significant SNPs associated with metabolic syndrome in the discovery phase of GWAS

\begin{tabular}{clllcrc}
\hline \multirow{2}{*}{ Chromosome } & \multirow{2}{*}{ SNP } & \multirow{2}{*}{ BP } & Nearby gene & Minor allele & \multicolumn{2}{c}{ p-value } \\
\cline { 5 - 7 } & & & & & Unadjusted & Bonferroni-adjusted \\
\hline 12 & rs11066280 & 111302166 & C12orf51 & T & $1.38 \mathrm{E}-07$ & 0.043 \\
12 & rs2074356 & 111129784 & C12orf51 & T & $4.25 \mathrm{E}-07$ & 0.133 \\
\hline 12 & rs12229654 & 109898844 & MYL2 & G & $3.00 \mathrm{E}-06$ & 0.937 \\
\hline
\end{tabular}

SNP, single-nucleotide polymorphism; GWAS, genome-wide association study; BP, base pair.

Table 3. Top ten significant GSEA associated with metabolic syndrome at the 75th percentile cutoff

\begin{tabular}{|c|c|c|c|c|c|}
\hline \multirow[b]{2}{*}{ Database } & \multirow[b]{2}{*}{ Biological pathway or gene set } & \multicolumn{4}{|c|}{ 75\% Cutoff (top 25\%) } \\
\hline & & $\begin{array}{l}\text { Nominal GSEA } \\
p \text {-value }\end{array}$ & $\begin{array}{c}\text { FDR } \\
\text { p-value }\end{array}$ & $\begin{array}{l}\text { Expected } \\
\text { genes }\end{array}$ & $\begin{array}{l}\text { Observed } \\
\text { genes }\end{array}$ \\
\hline GO term & Electron carrier activity & $<0.001$ & 0.094 & 27 & 46 \\
\hline Reactome & Signaling by PDGF & $<0.001$ & 0.105 & 9 & 19 \\
\hline GO term & MAPKKK cascade & 0.001 & 0.414 & 6 & 13 \\
\hline GO term & PDGF binding & 0.002 & 0.385 & 2 & 6 \\
\hline PANTHER molecular function & Nucleic acid binding & 0.003 & 0.343 & 106 & 131 \\
\hline Ingenuity & PPAR signaling & 0.003 & 0.113 & 3 & 8 \\
\hline GO term & $\begin{array}{l}\text { Negative regulation of gene-specific } \\
\text { transcription from RNA polymerase II promoter }\end{array}$ & 0.003 & 0.684 & 7 & 14 \\
\hline PANTHER molecular function & Non-motor microtubule-binding protein & 0.004 & 0.594 & 9 & 17 \\
\hline GO term & Protein secretion & 0.004 & 0.655 & 3 & 7 \\
\hline GO term & DNA repair & 0.004 & 0.847 & 31 & 45 \\
\hline
\end{tabular}

GSEA, gene set enrichment analysis; FDR, false discovery rate; GO, gene ontology; PDGF, platelet-derived growth factor; MAPKKK, mitogen-activated protein kinase kinase kinase; PANTHER, protein analysis through evolutionary relationships; PPAR, peroxisome proliferator-activated receptor. 


\section{Results}

A total of 8,842 subjects (4,183 men and 4,659 women) were involved in the study. Of them, 3,253 (36.8\%) had MetS. Clinical characteristics of subjects with and without MetS are shown in Table 1. Individuals with MetS were older, with higher BMI, systolic BP, triglycerides, and fasting plasma glucose and lower HDL-cholesterol levels compared to subjects without MetS.

In the discovery set of the GWAS, three SNPs associated with MetS were identified, demonstrated in Table 2. SNPs from chromosome 12, including rs11066280, rs2074356, and rs12229654, had a p $<5 \times 10^{-6}$. From these SNPs, only rs11066280 satisfied the Bonferroni-corrected cutoff (unadjusted $\mathrm{p}<1.38 \times 10^{-7}$, Bonferroni-adjusted $\mathrm{p}<0.05$ ).

The top 10 significant biological pathways or gene sets associated with MetS at the 75th percentile cutoff are shown in Table 3. The pathways were as follows: electron carrier activity (gene ontology [GO] term), signaling by plateletderived growth factor (PDGF) (Reactome), mitogenactivated protein kinase kinase kinase (MAPKKK) cascade (GO term), PDGF binding (GO term), nucleic acid binding (protein analysis through evolutionary relationships [PANTHER] molecular function), PPAR signaling (Ingenuity), negative regulation of gene-specific transcription from RNA polymerase II promoter (GO term), non-motor microtubule-binding protein (PANTHER molecular function), protein secretion (GO term), and DNA repair (GO term). At the FDR level, although all pathways were above 0.05, the pathway of electron carrier activity had an FDR value $<0.1$, and the pathways of signaling by PDGF and PPAR signaling showed an FDR $<0.2$.

\section{Discussion}

In this study, through pathway analysis of MetS, important pathways, including electron carrier activity, signaling by PDGF, MAPKKK cascade, PDGF binding, nucleic acid binding, PPAR signaling, negative regulation of genespecific transcription from RNA polymerase II promoter, non-motor microtubule binding protein, protein secretion, and DNA repair, were identified.

In the previous GWAS using KARE cohorts, rs 11066280 and rs2074356 in chromosome 12q24.13, near the chromosome 12 open reading frame, human C12orf51 (C12orf51), and rs12229654 in chromosome 12q24.11, near myosin, light chain 2 (MYL2) were identified to be associated with HDL-cholesterol, hypertension, T2DM, and dyslipidemia $[14,34]$. Drinking behavior was also associated with rs11066280 (C12orf51) in Korean men and Han Chinese [34, 35]. In other published GWASs on BMI, important variants on loci near/in FTO, MC4R, and transmembrane protein 18 (TMEM18) were associated with BMI, the latter also having a strong association with BMI in children [36]. Genetic variants in zinc finger protein 259 (ZNF259), lipoprotein lipase (LPL), and APOA5 were also associated with MetS [37]. In the GWAS of European Americans and Finnish cohorts, APOC1 was related with dyslipidemia and central obesity, and the gene cluster region in SNP rs964184, near/in gene $A P O A 1 / C 3 / A 4 / A 5$, was associated with MetS $[3,38]$.

Through MAGENTA analysis, pathways related with electron carrier activity and PDGF signaling and binding, as well as PPAR signaling, were identified as some of the top ranking pathways associated with MetS. Electron carrier activity may be related with electron transport activity in the mitochondria. Abnormal regulation of mitochondrial function is associated with factors, such as reduced electron transport chain, which can lead to insulin resistance and MetS [39, 40]. In obese and diabetic patients, fewer and diminished mitochondrial electron transport enzymes, especially complex I, were observed in the skeletal muscle [41-43]. Defects in the electron transport chain can impair carbohydrate metabolism, affecting the tricarboxylic acid cycle and limiting ATP activity, which could result in lactic acidosis [44]. In addition, mitochondria respiratory chains are major sites of reactive oxygen species (ROS) production, and excess electrons can increase ROS, stimulating proinflammatory processes and mutagenesis, contributing to mitochondrial dysfunction $[40,45]$.

Pathways related to PDGF binding and signaling and the MAPKKK cascade were also associated with MetS in this study. The PDGF signaling pathway has been identified to be associated with BMI [29]. PDGF is an important activator of cell proliferation and migration, mediated by the mitogenactivated protein kinase (MAPK) family, and PDGF signaling regulates angiogenesis [46, 47]. In animal studies, PDGFmediated pathways played a crucial role in healing myocardial infarction, myocardial fibrosis, and defects in the pathway lead to prolongation of inflammation [48, 49]. In a human study, serum PDGF isoform b levels were lower in individuals with MetS, while increased PDGF expression with elevated urinary PDGF-BB was seen in patients with diabetic nephropathy [50, 51]. MAPK pathways are involved in adipogenesis and metabolic homeostasis, and defects in these pathways due to factors, such as oxidative stress, can lead to abnormal adipose regulation, insulin resistance, and obesity $[52,53]$. In addition, increased MAPK signaling had a detrimental effect on $\beta$-cell function and insulin homeostasis, which could contribute to the development of MetS [54]. The PPAR isotypes PPAR- $\alpha,-\delta$, and $-\gamma$ play an important role in lipid and glucose metabolism [55]. PPAR- $\alpha$ 
is expressed in tissues, including skeletal muscle and liver, regulating lipid metabolism and inflammatory processes, whereas PPAR- $\delta$ and PPAR- $\gamma$ are involved in adipocyte differentiation [56]. Genetic variations in PPAR can affect glucose uptake, fasting glucose levels, and BMI [57-59]. In a GWAS of T2DM in a Finnish population, variants near PPAR- $\gamma$ were associated with T2DM [60]. In a Korean study, polymorphisms in PPAR- $\delta$ were related with BMI and fasting glucose in non-diabetics [61].

Other pathways related with nucleic acids, such as RNA and DNA, as well as pathways of protein secretion were also associated with MetS. MicroRNAs regulate the action and secretion of insulin, as well as lipid metabolism, playing an important role in the pathogenesis of diabetes, obesity, and cancer [62-64]. Abnormal expression of microRNAs in pancreatic beta-cells affects beta-cell function and insulin secretion [65]. MicroRNA expression is also related to appetite control in the brain; neural signaling in the muscle, pancreas, and liver; and biological processes of lipid metabolism, which are linked to obesity $[65,66]$. In addition, microRNA-33 is an important regulator of lipid metabolism, regulating insulin signaling and fatty acid regulation, and may be a therapeutic target for treating MetS [67]. Mitochondrial dysfunction is an important cause, leading to diabetes [68]. DNA damage in mitochondria and vascular cells can have a detrimental effect on mitochondrial function, increasing ROS production and promoting atherosclerosis $[68,69]$. Variations in mitochondrial DNA can also lead to MetS, hyperinsulinemia, and T2DM [70-72]. In addition, insulin also regulates DNA repair, and a chronic hyperglycemic state can damage DNA, contributing to genomic mutation, which can be associated with cancer [73]. Abnormal protein secretion can affect metabolic traits, proven through studies demonstrating increased secretion of fatty acid-binding protein 4 (FABP4), and frizzled-related protein 4 (SFRP4), associated with obesity, insulin resistance, and abnormal insulin sensitivity [74-76]. Retinolbinding protein 4 (RBP4), expressed in adipocytes and liver, showed a positive correlation with MetS in a Chinese population, associated with insulin resistance and dyslipidemia $[77,78]$.

The exact association between the pathway of non-motor microtubule binding and MetS can not be explained. However, studies have shown non-motor microtubule binding sites to have an important role in mitosis and to be essential in the embryonic development of Drosophila [79]. More studies will be needed to elucidate the association between non-motor microtubule binding and MetS.

One of the strengths of this study is the usage of a pathway-based approach to further analyze the KARE GWAS datasets. Pathway-based approaches of MetS in Asians are relatively scarce. Therefore, this study might help further elucidate the pathophysiology of MetS. Although the pathways identified in our study did not show an FDR value $<0.05$, important pathways related with BMI, lipid and glucose metabolism, including signaling by PDGF and PPAR signaling, had an FDR $<0.2$. Other pathway-based approaches will be needed to further validate the identified pathways.

Pathway-based analysis has its strengths in improving the interpretability of the GWAS. However, current pathway analysis tools are limited in finding a well-defined pathway, and their isolated characteristics make it hard to combine them with other analyses [80]. In addition, the limited knowledge base and imprecision of gene annotations restricts their usage and integration with other analysis methods [81]. Therefore, these limitations will need to be improved to generalize this approach and increase its applicability.

In conclusion, through pathway analysis of MetS, significant biological pathways associated with lipid and glucose metabolism could be identified, and these results might contribute to the understanding of MetS.

\section{Acknowledgments}

This work was supported by grants from the Korea Centers for Disease Control and Prevention, Republic of Korea (4845-301, 4851-302, 4851-307) and the National Research Foundation of Korea (NRF) funded by the Ministry of Education (NRF-2013R1A1A2062702).

\section{References}

1. de Carvalho Vidigal F, Bressan J, Babio N, Salas-Salvadó J. Prevalence of metabolic syndrome in Brazilian adults: a systematic review. BMC Public Health 2013;13:1198.

2. Márquez-Sandoval F, Macedo-Ojeda G, Viramontes-Hörner D, Fernández Ballart JD, Salas Salvadó J,Vizmanos B. The prevalence of metabolic syndrome in Latin America: a systematic review. Public Health Nutr 2011;14:1702-1713.

3. Aguilera CM, Olza J, Gil A. Genetic susceptibility to obesity and metabolic syndrome in childhood. Nutr Hosp 2013;28 Suppl 5:44-55.

4. Hoang KC, Le TV, Wong ND. The metabolic syndrome in East Asians. J Cardiometab Syndr 2007;2:276-282.

5. Nestel P, Lyu R, Low LP, Sheu WH, Nitiyanant W, Saito I, et al. Metabolic syndrome: recent prevalence in East and Southeast Asian populations. Asia Pac J Clin Nutr 2007;16:362-367.

6. Whitaker RC, Wright JA, Pepe MS, Seidel KD, Dietz WH. Predicting obesity in young adulthood from childhood and parental obesity. N Engl J Med 1997;337:869-873.

7. Whitaker RC. Predicting preschooler obesity at birth: the role of maternal obesity in early pregnancy. Pediatrics 2004;114: 
e29-e36.

8. Ristow M, Müller-Wieland D, Pfeiffer A, Krone W, Kahn CR. Obesity associated with a mutation in a genetic regulator of adipocyte differentiation. N Engl J Med 1998;339:953-959.

9. Peters KE, Beilby J, Cadby G, Warrington NM, Bruce DG, Davis WA, et al. A comprehensive investigation of variants in genes encoding adiponectin (ADIPOQ) and its receptors (ADIPOR1/R2), and their association with serum adiponectin, type 2 diabetes, insulin resistance and the metabolic syndrome. BMC Med Genet 2013;14:15.

10. Joy T, Lahiry P, Pollex RL, Hegele RA. Genetics of metabolic syndrome. Curr Diab Rep 2008;8:141-148.

11. Fall T, Ingelsson E. Genome-wide association studies of obesity and metabolic syndrome. Mol Cell Endocrinol 2014;382: 740-757.

12. Vimaleswaran KS, Tachmazidou I, Zhao JH, Hirschhorn JN, Dudbridge F, Loos RJ. Candidate genes for obesity-susceptibility show enriched association within a large genome-wide association study for BMI. Hum Mol Genet 2012;21:4537-4542.

13. Kristiansson K, Perola M, Tikkanen E, Kettunen J, Surakka I, Havulinna AS, et al. Genome-wide screen for metabolic syndrome susceptibility loci reveals strong lipid gene contribution but no evidence for common genetic basis for clustering of metabolic syndrome traits. Circ Cardiovasc Genet 2012;5:242-249.

14. Kim YJ, Go MJ, Hu C, Hong CB, Kim YK, Lee JY, et al. Large-scale genome-wide association studies in East Asians identify new genetic loci influencing metabolic traits. Nat Genet 2011;43:990-995.

15. Lee BY, Shin DH, Cho S, Seo KS, Kim H. Genome-wide analysis of copy number variations reveals that aging processes influence body fat distribution in Korea Associated Resource (KARE) cohorts. Hum Genet 2012;131:1795-1804.

16. Cho YS, Go MJ, Kim YJ, Heo JY, Oh JH, Ban HJ, et al. A large-scale genome-wide association study of Asian populations uncovers genetic factors influencing eight quantitative traits. Nat Genet 2009;41:527-534.

17. Hirschhorn JN, Daly MJ. Genome-wide association studies for common diseases and complex traits. Nat Rev Genet 2005;6: 95-108.

18. de Bakker PI, Yelensky R, Pe'er I, Gabriel SB, Daly MJ, Altshuler D. Efficiency and power in genetic association studies. Nat Genet 2005;37:1217-1223.

19. Cantor RM, Lange K, Sinsheimer JS. Prioritizing GWAS results: a review of statistical methods and recommendations for their application. Am J Hum Genet 2010;86:6-22.

20. Teo YY. Common statistical issues in genome-wide association studies: a review on power, data quality control, genotype calling and population structure. Curr Opin Lipidol 2008;19: 133-143.

21. Stringer S, Wray NR, Kahn RS, Derks EM. Underestimated effect sizes in GWAS: fundamental limitations of single SNP analysis for dichotomous phenotypes. PLoS One 2011;6: e27964.

22. Zeggini E, Scott LJ, Saxena R, Voight BF, Marchini JL, Hu T, et al. Meta-analysis of genome-wide association data and large-scale replication identifies additional susceptibility loci for type 2 diabetes. Nat Genet 2008;40:638-645.

23. Barrett JC, Hansoul S, Nicolae DL, Cho JH, Duerr RH, Rioux JD, et al. Genome-wide association defines more than 30 distinct susceptibility loci for Crohn's disease. Nat Genet 2008;40: 955-962.

24. Ramanan VK, Shen L, Moore JH, Saykin AJ. Pathway analysis of genomic data: concepts, methods, and prospects for future development. Trends Genet 2012;28:323-332.

25. Wang K, Li M, Hakonarson H. Analysing biological pathways in genome-wide association studies. Nat Rev Genet 2010;11: 843-854.

26. Shahbaba B, Shachaf CM, Yu Z. A pathway analysis method for genome-wide association studies. Stat Med 2012;31:9881000.

27. Segrè AV; DIAGRAM Consortium; MAGIC investigators, Groop L, Mootha VK, Daly MJ, et al. Common inherited variation in mitochondrial genes is not enriched for associations with type 2 diabetes or related glycemic traits. PLoS Genet 2010;6:e1001058.

28. Morris AP, Voight BF, Teslovich TM, Ferreira T, Segrè AV, Steinthorsdottir V, et al. Large-scale association analysis provides insights into the genetic architecture and pathophysiology of type 2 diabetes. Nat Genet 2012;44:981-990.

29. Speliotes EK, Willer CJ, Berndt SI, Monda KL, Thorleifsson G, Jackson AU, et al. Association analyses of 249,796 individuals reveal 18 new loci associated with body mass index. Nat Genet 2010;42:937-948.

30. National Cholesterol Education Program (NCEP) Expert Panel on Detection, Evaluation, and Treatment of High Blood Cholesterol in Adults (Adult Treatment Panel III). Third Report of the National Cholesterol Education Program (NCEP) Expert Panel on Detection, Evaluation, and Treatment of High Blood Cholesterol in Adults (Adult Treatment Panel III) final report. Circulation 2002;106:3143-3421.

31. Grundy SM, Cleeman JI, Daniels SR, Donato KA, Eckel RH, Franklin BA, et al. Diagnosis and management of the metabolic syndrome: an American Heart Association/National Heart, Lung, and Blood Institute Scientific Statement. Circulation 2005;112:2735-2752.

32. Purcell S, Neale B, Todd-Brown K, Thomas L, Ferreira MA, Bender D, et al. PLINK: a tool set for whole-genome association and population-based linkage analyses. Am J Hum Genet 2007;81:559-575.

33. Zhai G, Teumer A, Stolk L, Perry JR, Vandenput L, Coviello $\mathrm{AD}$, et al. Eight common genetic variants associated with serum DHEAS levels suggest a key role in ageing mechanisms. PLoS Genet 2011;7:e1002025.

34. Heo SG, Hwang JY, Uhmn S, Go MJ, Oh B, Lee JY, et al. Male-specific genetic effect on hypertension and metabolic disorders. Hum Genet 2014;133:311-319.

35. Baik I, Cho NH, Kim SH, Han BG, Shin C. Genome-wide association studies identify genetic loci related to alcohol consumption in Korean men. Am J Clin Nutr 2011;93:809-816.

36. Frayling TM, Timpson NJ, Weedon MN, Zeggini E, Freathy $\mathrm{RM}$, Lindgren CM, et al. A common variant in the FTO gene is associated with body mass index and predisposes to childhood and adult obesity. Science 2007;316:889-894. 
37. Kraja AT, Vaidya D, Pankow JS, Goodarzi MO, Assimes TL, Kullo IJ, et al. A bivariate genome-wide approach to metabolic syndrome: STAMPEED consortium. Diabetes 2011;60:13291339.

38. Avery CL, He Q, North KE, Ambite JL, Boerwinkle E, Fornage $\mathrm{M}$, et al. A phenomics-based strategy identifies loci on APOC1, $B R A P$, and PLCG1 associated with metabolic syndrome phenotype domains. PLoS Genet 2011;7:e1002322.

39. Ren J, Pulakat L, Whaley-Connell A, Sowers JR. Mitochondrial biogenesis in the metabolic syndrome and cardiovascular disease. J Mol Med (Berl) 2010;88:993-1001.

40. Kim JA, Wei Y, Sowers JR. Role of mitochondrial dysfunction in insulin resistance. Circ Res 2008;102:401-414.

41. Patti ME, Butte AJ, Crunkhorn S, Cusi K, Berria R, Kashyap S, et al. Coordinated reduction of genes of oxidative metabolism in humans with insulin resistance and diabetes: Potential role of PGC1 and NRF1. Proc Natl Acad Sci U S A 2003;100:84668471.

42. Ritov VB, Menshikova EV, He J, Ferrell RE, Goodpaster BH, Kelley DE. Deficiency of subsarcolemmal mitochondria in obesity and type 2 diabetes. Diabetes 2005;54:8-14.

43. Kelley DE, He J, Menshikova EV, Ritov VB. Dysfunction of mitochondria in human skeletal muscle in type 2 diabetes. Diabetes 2002;51:2944-2950.

44. Adams PL, Turnbull DM. Disorders of the electron transport chain. J Inherit Metab Dis 1996;19:463-469.

45. Choksi KB, Boylston WH, Rabek JP, Widger WR, Papaconstantinou J. Oxidatively damaged proteins of heart mitochondrial electron transport complexes. Biochim Biophys Acta 2004;1688:95-101.

46. Harper L, Kashiwagi Y, Pusey CD, Hendry BM, Domin J. Platelet-derived growth factor reorganizes the actin cytoskeleton through 3-phosphoinositide-dependent and 3-phosphoinositide-independent mechanisms in human mesangial cells. Nephron Physiol 2007;107:p45-p56.

47. Carmeliet P. Angiogenesis in health and disease. Nat Med 2003;9:653-660.

48. Zymek P, Bujak M, Chatila K, Cieslak A, Thakker G, Entman $\mathrm{ML}$, et al. The role of platelet-derived growth factor signaling in healing myocardial infarcts. J Am Coll Cardiol 2006;48:23152323.

49. Fan B, Ma L, Li Q, Wang L, Zhou J, Wu J. Role of PDGFs/PDGFRs signaling pathway in myocardial fibrosis of DOCA/salt hypertensive rats. Int J Clin Exp Pathol 2014;7: 16-27.

50. Tisato V, Toffoli B, Monasta L, Bernardi S, Candido R, Zauli G, et al. Patients affected by metabolic syndrome show decreased levels of circulating platelet derived growth factor (PDGF)BB. Clin Nutr 2013;32:259-264.

51. Bessa SS, Hussein TA, Morad MA, Amer AM. Urinary platelet-derived growth factor-BB as an early marker of nephropathy in patients with type 2 diabetes: an Egyptian study. Ren Fail 2012;34:670-675.

52. Murdolo G, Bartolini D, Tortoioli C, Piroddi M, Iuliano L, Galli F. Lipokines and oxysterols: novel adipose-derived lipid hormones linking adipose dysfunction and insulin resistance. Free Radic Biol Med 2013;65:811-820.
53. Bost F, Aouadi M, Caron L, Binétruy B. The role of MAPKs in adipocyte differentiation and obesity. Biochimie 2005;87:5156.

54. Gehart H, Kumpf S, Ittner A, Ricci R. MAPK signalling in cellular metabolism: stress or wellness? EMBO Rep 2010;11:834840.

55. Azhar S. Peroxisome proliferator-activated receptors, metabolic syndrome and cardiovascular disease. Future Cardiol 2010;6:657-691.

56. Corzo C, Griffin PR. Targeting the peroxisome proliferatoractivated receptor-gamma to counter the inflammatory milieu in obesity. Diabetes Metab J 2013;37:395-403.

57. Vänttinen M, Nuutila P, Kuulasmaa T, Pihlajamäki J, Hällsten $\mathrm{K}$, Virtanen KA, et al. Single nucleotide polymorphisms in the peroxisome proliferator-activated receptor delta gene are associated with skeletal muscle glucose uptake. Diabetes 2005; 54:3587-3591.

58. Hu C, Jia W, Fang Q, Zhang R, Wang C, Lu J, et al. Peroxisome proliferator-activated receptor (PPAR) delta genetic polymorphism and its association with insulin resistance index and fasting plasma glucose concentrations in Chinese subjects. Diabet Med 2006;23:1307-1312.

59. Aberle J, Hopfer I, Beil FU, Seedorf U. Association of peroxisome proliferator-activated receptor delta $+294 \mathrm{~T} / \mathrm{C}$ with body mass index and interaction with peroxisome proliferator-activated receptor alpha L162V. Int J Obes (Lond) 2006;30:1709-1713.

60. Scott LJ, Mohlke KL, Bonnycastle LL, Willer CJ, Li Y, Duren $\mathrm{WL}$, et al. A genome-wide association study of type 2 diabetes in Finns detects multiple susceptibility variants. Science 2007;316:1341-1345.

61. Shin HD, Park BL, Kim LH, Jung HS, Cho YM, Moon MK, et al. Genetic polymorphisms in peroxisome proliferator-activated receptor delta associated with obesity. Diabetes 2004;53:847851.

62. Tang X, Tang G, Ozcan S. Role of microRNAs in diabetes. Biochim Biophys Acta 2008;1779:697-701.

63. Poy MN, Spranger M, Stoffel M. microRNAs and the regulation of glucose and lipid metabolism. Diabetes Obes Metab 2007;9 Suppl 2:67-73.

64. Ramírez CM, Goedeke L, Fernández-Hernando C. "Micromanaging" metabolic syndrome. Cell Cycle 2011;10:32493252.

65. Heneghan HM, Miller N, Kerin MJ. Role of microRNAs in obesity and the metabolic syndrome. Obes Rev 2010;11:354-361.

66. Esau C, Davis S, Murray SF, Yu XX, Pandey SK, Pear M, et al. miR-122 regulation of lipid metabolism revealed by in vivo antisense targeting. Cell Metab 2006;3:87-98.

67. Gharipour M, Sadeghi M. Pivotal role of microRNA-33 in metabolic syndrome: a systematic review. ARYA Atheroscler 2013;9:372-376.

68. Wang PW, Lin TK, Weng SW, Liou CW. Mitochondrial DNA variants in the pathogenesis of type 2 diabetes - relevance of asian population studies. Rev Diabet Stud 2009;6:237-246.

69. Mercer JR, Cheng KK, Figg N, Gorenne I, Mahmoudi M, Griffin J, et al. DNA damage links mitochondrial dysfunction to atherosclerosis and the metabolic syndrome. Circ Res 
2010;107:1021-1031.

70. Weng SW, Liou CW, Lin TK, Wei YH, Lee CF, Eng HL, et al. Association of mitochondrial deoxyribonucleic acid 16189 variant ( $\mathrm{T}->\mathrm{C}$ transition) with metabolic syndrome in Chinese adults. J Clin Endocrinol Metab 2005;90:5037-5040.

71. Liou CW, Lin TK, Huei Weng H, Lee CF, Chen TL, Wei YH, et al. A common mitochondrial DNA variant and increased body mass index as associated factors for development of type 2 diabetes: additive effects of genetic and environmental factors. $J$ Clin Endocrinol Metab 2007;92:235-239.

72. Poulton J, Brown MS, Cooper A, Marchington DR, Phillips DI. A common mitochondrial DNA variant is associated with insulin resistance in adult life. Diabetologia 1998;41:54-58.

73. Blasiak J, Arabski M, Krupa R, Wozniak K, Zadrozny M, Kasznicki J, et al. DNA damage and repair in type 2 diabetes mellitus. Mutat Res 2004;554:297-304.

74. Cabré A, Lázaro I, Girona J, Manzanares JM, Marimón F, Plana $\mathrm{N}$, et al. Fatty acid binding protein 4 is increased in metabolic syndrome and with thiazolidinedione treatment in diabetic patients. Atherosclerosis 2007;195:e150-e158.

75. Cabré A, Lázaro I, Girona J, Manzanares JM, Marimón F, Plana $\mathrm{N}$, et al. Plasma fatty acid-binding protein 4 increases with renal dysfunction in type 2 diabetic patients without micro- albuminuria. Clin Chem 2008;54:181-187.

76. Mahdi T, Hänzelmann S, Salehi A, Muhammed SJ, Reinbothe $\mathrm{TM}$, Tang Y, et al. Secreted frizzled-related protein 4 reduces insulin secretion and is overexpressed in type 2 diabetes. Cell Metab 2012;16:625-633.

77. Qi Q, Yu Z, Ye X, Zhao F, Huang P, Hu FB, et al. Elevated retinol-binding protein 4 levels are associated with metabolic syndrome in Chinese people. J Clin Endocrinol Metab 2007;92: 4827-4834.

78. Liu Y, Wang D, Li D, Sun R, Xia M. Associations of retinol-binding protein 4 with oxidative stress, inflammatory markers, and metabolic syndrome in a middle-aged and elderly Chinese population. Diabetol Metab Syndr 2014;6:25.

79. Zhang G, Beati H, Nilsson J, Wodarz A. The Drosophila microtubule-associated protein mars stabilizes mitotic spindles by crosslinking microtubules through its $\mathrm{N}$-terminal region. PLoS One 2013;8:e60596.

80. Kelder T, Conklin BR, Evelo CT, Pico AR. Finding the right questions: exploratory pathway analysis to enhance biological discovery in large datasets. PLoS Biol 2010;8:e1000472.

81. Khatri P, Sirota M, Butte AJ. Ten years of pathway analysis: current approaches and outstanding challenges. PLoS Comput Biol 2012;8:e1002375. 